\title{
NOTE ON COLLOIDAL FERRIC HYDROXIDE IN SEA WATER
}

\author{
By H. W. Harvey, Sc.D., M.A. \\ Hydrographer at the Plymouth Laboratory
}

If a sol of colloidal ferric hydroxide is added to sea water, or if the hydroxide is formed in sea water by adding a solution of an iron salt, the aggregated molecules of hydroxide coalesce to form flocs which fall rather rapidly as a precipitate. When several thousand mg. of iron are added per cubic metre of sea water, flocculation is immediate; on adding $300-500 \mathrm{mg}$. Fe per $\mathrm{m}^{3}$ in sufficiently dilute solution $\left(\mathrm{IO}^{-4}\right.$ or $1 \mathrm{IO}^{-5} \mathrm{M}$ ) flocculation and sedimentation may be delayed for several days. Although this quantity is over twenty times as much as ordinarily occurs in the sea, it seemed rather remarkable that the waters of the open ocean could maintain any material quantity of ferric hydroxide in suspension, since it would there have many years in which to flocculate and fall.

Waksman had suggested that much of the iron in sea water may be in the form of iron humates derived from the breakdown of organisms, and he had obtained evidence that such humates were compounds of lignoproteinates.

Since ferric hydroxide in sea water, in spite of its great insolubility, is utilized by diatoms, some experiments concerning its nature were made, and an account of some of these may be of use to others interested in the same field.

\section{Colloidal FerRic Hydroxide adsorbed on EMUlsoids}

A number of sols have been prepared by adding $M / 500$ ferrous or ferric salts containing a small quantity of various emulsoids to an equal volume of sodium hydroxide, of such concentration that the resultant liquid was alkaline ( $p \mathrm{H} \mathrm{8-10).}$

Sols prepared in this way and containing one to eight times more gum arabic by weight than iron, when added to sea water, giving a final concentration of 2000-5000 mg. per m. ${ }^{3}$, did not flocculate for several weeks. They also gave a clear solution in normal sodium hydroxide.

Sols containing four to ten times more starch by weight than iron when added to sea water did not flocculate for several days. On standing or boiling, the sols darken in colour with a rise in hydrogen-ion concentration, suggesting that hydrolysis is not completed for some time even in such alkaline media. Boiled sols containing ten times more starch than iron when added to sea water did not flocculate for many weeks, and gave a clear solution in normal sodium hydroxide.

Sols containing two to ten times as much albumen as iron, when added to sea water, remained in suspension for some hours or days. 
Sols containing two to four times as much agar-agar as iron when added to sea water did not flocculate until after 2 or 3 days. The precipitate formed then appears more voluminous and, after shaking, it settles less rapidly than a precipitate formed from an equivalent quantity of iron salt, or sol, without emulsoid. A notable instance of this occurred on adding such a sol to sea water to the extent of $2240 \mathrm{mg}$. Fe and $8000 \mathrm{mg}$. agar per m. ${ }^{3}$ Flocculation and sedimentation were observed after 3 days; a week later, when sedimentation appeared to be complete, the flask was shaken, and thereafter much of the precipitate remained in suspension throughout a period of 2 months. The experiment was repeated.

In order to account for an emulsoid "protecting" a sol from flocculating in a solution of an electrolyte, a theory has been advanced that the emulsoid forms a shell around the irreversible colloidal particle. The presence of this shell prevents the particles coalescing by either (i) offering a material obstacle or (ii) preventing the cause which brings about coalescence of the particles, that is the loss of their electric charges (Burton, I916, p. I70). The degree of protection is attributed by Freundlich (1925, p. I25) to the "uniformity, closeness and solidity" of the shell or envelope of emulsoid.

In all the instances examined protection has been given to many molecules of ferric hydroxide by a single molecule of emulsoid. Even with ten times less iron, there will be many more molecules of ferric hydroxide than emulsoid, owing to the very high molecular weight of the latter. This indicates that a shell of emulsoid was not formed round the hydroxide.

In addition to altering the tendency of colloidal hydroxide to flocculate, it was observed that small quantities of emulsoid also reduced the rate at which the colloidal hydroxide dissolved in dilute acids or in sodium citrate.

Cooper's investigations (1935) have shown that iron in the sea is probably taken up by phytoplankton and given back to the water several times in the course of a year. When unicellular plants are eaten, broken and defaecated by zooplankton, or die, iron released from organic combination will be hydrolysed in the alkaline sea water. This takes place in the presence of organic matterthe protein of the diatom, its surrounding slime, etc.-so a certain measure of protection may be expected. Colloidal particles of iron hydroxide adsorbed upon the plant (Harvey, I937) are also likely to be set free in a more or less "protected" state.

It seems therefore that two factors tend to keep ferric hydroxide in colloidal suspension in the sea, their very low concentration and their "protection".

If flocculation takes place, sedimentation of an unprotected sol proceeds more or less rapidly. In the open ocean, at a distance from the land, the upper layers are beyond the influence of land drainage, and where marked layering exists, any considerable renewal of their iron content from below would seem improbable. In wide expanses of ocean in the tropics, the water remains in the upper warmer layers for several years, time enough for flocculation and sedimentation of unprotected ferric hydroxide to take place and to leave the water 
iron-free, and in consequence barren of plant life, but not necessarily barren of phosphates and nitrates. This would only occur if turbulence did not keep the upper layers supplied with (flocculated) particles from below. That turbulence may be sufficient to do this, in spite of layering, is suggested in Seiwell's (1935) interesting conclusions concerning the vertical transference of phosphate and oxygen in the open ocean.

\section{IRON HuMATES}

Waksman (1932) has suggested that much of the iron in sea water may be in combination with humic substances, and he has shown that "natural" humic acids are very similar to lignoproteinates in composition, in properties, and in resisting bacterial attack. Both combine with or adsorb iron salts, in small amount compared with their own weight, and give a product which dissolves in alkali to a clear solution.

A few observations were made on iron-containing compounds of this nature.

(i) Ferric chloride was added to lignin. The product was soluble in dilute sodium hydroxide, but on raising the concentration to $0.5 \mathrm{~N}$, ferric hydroxide precipitated.

(ii) Ferric chloride and a small quantity of peptone were added to lignin. The product, soluble in dilute alkali, gave a clear solution in normal sodium hydroxide. It was partly precipitated in sea water.

(iii) Ferric chloride was added to "humic acid", prepared from peat by repeatedly dissolving in alkali and precipitating with acid. The product gave a clear solution in normal sodium hydroxide and was partly precipitated in sea water.

(iv) I am indebted to Prof. S. A. Waksman for a preparation of ligno-caseinate containing almost $2 \%$ of iron, similar to that used by Gran (I933) as a source of iron for the growth of diatoms. It resembled the peat humic acid and the lignin-peptone products in giving a clear solution in strong alkali and in being partly precipitated in sea water. After several weeks sea water was found to have retained in solution $5 \%$ of the iron added in this form. (I am indebted to Dr L. H. N. Cooper for making estimations of the iron remaining in solution.)

The following experiment suggests that it is the iron remaining in solution which is utilized by diatoms.

$\mathrm{N}$ I2. Growth of Biddulphia mobiliensis in cultures containing iron as Waksman's artificial humate and as ammonium ferricitrate, added to water enriched with phosphate nitrate and silicate.

Sea water enriched N, P, Si, with $400 \mathrm{mg} . \mathrm{Fe} / \mathrm{m}^{3}$ as artificial humate added 20 days previous to insemination $\quad \begin{array}{lllll} & \ldots & \ldots & \ldots & \ldots\end{array}$

$\%$ increase of diatoms

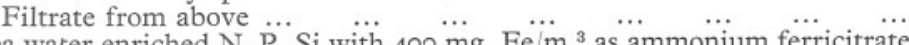

Sea water enriched $\mathrm{N}, \mathrm{P}, \mathrm{Si}$ with $400 \mathrm{mg}$. $\mathrm{Fe} / \mathrm{m}^{3}$ as ammonium ferricitrate
added 20 days previous to insemination
$\ldots$

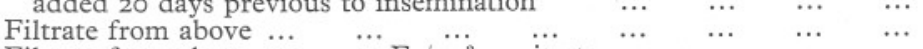

Filtrate from above $+400 \mathrm{mg} . \mathrm{Fe} / \mathrm{m}^{3}$ as citrate $\quad \ldots \quad \ldots \quad \ldots \quad \ldots$

The result of this experiment was confirmed. 
In experiments with Nitzschia closterium it was observed that addition of the ligno-casein product caused less rapid growth than iron citrate or hydroxide sol when added in amounts containing the same quantity of iron. With small additions $-5.6 \mathrm{mg}$. Fe per $\mathrm{m} .{ }^{3}$-its effect was much less.

\section{The Electric Charge on Colloidal Particles of Ferric Hydroxide}

Powis (1915) found that colloidal particles in a strongly alkaline sol $(0.002 \mathrm{~N} \mathrm{NaOH})$ carried an electronegative charge, and in an acid solution a positive charge. The polarity could be changed by suitably changing the reaction. He did not investigate the iso-electric point.

A ferric hydroxide sol was prepared having a $p \mathrm{H} c a .7 \cdot 4$ and the particles were found to carry an electropositive charge, moving towards the negative electrode in a cataphoresis tube at $5 \times 10^{-5} \mathrm{~cm}$. per volt per sec.

On the addition of four times as much gum arabic (an electronegative emulsoid) as there was iron, the polarity changed, the particles moving towards the positive electrode at $\mathrm{II} \cdot 8 \times \mathrm{IO}^{-5} \mathrm{~cm}$. per V. per sec.

When diluted with an equal quantity of sea water, this protected sol was found to have retained part of its electronegative charge, moving at $c a$. $3.7 \times 10^{-5} \mathrm{~cm}$. per V. per sec.

Two other sols were prepared, containing respectively twice and four times as much gum arabic as iron, added previous to the formation of hydroxide. In both experiments the colloid particles were electronegative, in the latter moving at $\mathrm{II} \times \mathrm{IO}^{-5} \mathrm{~cm}$. per V. per sec. and, after mixing with an equal volume of sea water, at $c a .6 \times 10^{-5} \mathrm{~cm}$. per V. per sec.

A second instance of change of polarity to that of the emulsoid was found on adding gum arabic to dialysed iron.

Albumen in a ferric hydroxide sol delays its flocculation in sea water. This emulsoid is electronegative in alkaline solution and electropositive in acid solution (Hardy, I899). An alkaline sol containing five times as much albumen as iron was found to be electronegative, moving at $10 \times 10^{-5} \mathrm{~cm}$. per V. per sec., while an acid sol prepared by adding albumen to dialysed iron was found to be electropositive, moving at $4 \times 10^{-5} \mathrm{~cm}$. per V. per sec. When mixed with sea water, no movement in an electric field could be detected, although a definite measure of protection had been afforded. This was also the case with an electronegative sol containing agar-agar. The method would not have allowed a small charge, remaining on the particles when in sea water, to have been detected.

\section{SUMMARY}

Colloidal ferric hydroxide flocculates in sea water, the less rapidly the greater the dilution. When formed in the presence of very small quantities of various emulsoids, it does not flocculate on adding to sea water or flocculates less rapidly. 
Many molecules of ferric hydroxide are adsorbed on and "protected" by one molecule of emulsoid. The shell theory of protection does not apply.

It is probable that ferric hydroxide in the sea is similarly adsorbed on emulsoids.

The nature and behaviour of iron humates is considered.

The electric charge carried by colloidal particles of ferric hydroxide has been determined, and it is found that when adsorbed on gum arabic, albumen or agar-agar they had the same polarity as the emulsoid.

\section{REFERENCES}

Burton, E. F., I9r6. The Physical Properties of Colloidal Solutions. London.

Cooper, L. H. N., I935. Iron in the sea. Proc. Roy. Soc., B, Vol. II8, p. 4I9.

Freundlich, H., 1925. The Elements of Colloidal Chemistry. London.

Gran, H. H., I933. Distribution of phytoplankton in the Gulf of Maine. Biol. Bull., Vol. 64 , p. I59.

Hardy, W. B., I899. On the coagulation of proteid by electricity. Fourn. Physiol., Vol. 24, p. 288.

Harvey, H. W., I937. The supply of iron to diatoms. Fourn. Mar. Biol. Assoc., Vol. xxir, p. 205 .

Powis, F., I9I5. Negative colloidal ferric hydroxide. Fourn. Chem. Soc., Vol. I07, p. 818 .

SeIwELL, H. R., I935. The annual organic production and nutrient salt requirements in the tropical western North Atlantic. Fourn. Cons. Int. Expl. Mer, Vol. x, p. 20.

Waksman, S. A., I933. Marine humus. Soil Science, Vol. 34, p. I25.

WaKsMan, S. A. \& IYER, K., I932. Synthesis of a humus nucleus. Fourn. Wash. Acad Sci., Vol. 22, p. 4I. 